\title{
Crítica do direito e teoria dos sistemas
}

\author{
Kolja Möller
}

Tradução do alemão de Patrícia da Silva Santos

Niklas Luhmann não era um crítico do direito e sempre contrariou as tentativas de abrir normativamente sua teoria jurídica (Luhmann, 1985). Recentemente surgiu, contudo, um amplo espectro de discussão que trabalha no sentido de tornar as reflexões de Luhmann frutíferas para uma crítica jurídica. A começar pelas controvérsias iniciais do direito reflexivo até os critical legal studies e a crítica do direito pós-colonial, as perspectivas teórico-sistêmicas são frequentemente retomadas ${ }^{1}$. Assim, não é de se admirar que o impulso para os principais pontos da teoria contemporânea do direito, como o direito transnacional, a mudança constitucional da sociedade mundial ou a relação entre direito e poder, inspiram-se frequentemente no reservatório da teoria dos sistemas. Fala-se até mesmo de um luhmannianismo de esquerda ${ }^{2}$. Da mesma forma que os hegelianos de esquerda serviram-se da filosofia social hegeliana como ponto de partida para uma crítica social sem partilhar de suas afirmações parcialmente conservadoras, a teoria da diferenciação funcional é também empregada, reescrita ou variada até tornar-se irreconhecível para legitimar questões da crítica do direito.

$\mathrm{Na}$ sequência será examinada a seguinte questão: em que sentido esse programa herdou a doutrina crítica do Estado de direito, que tomou sua configuração outrora na primeira geração da Escola de Frankfurt nos anos de 1920 e 1930 (Kirchheimer, 1976; Neumann, 1967)? A tese é de que o ingresso da teoria sistêmica na teoria jurídica deve lidar novamente com a relação de tensão

1.Em relação ao direito reflexivo, ver Teubner (1983; 1989); à “autopoiesis crítica”, Philippopoulos-Mihalopoulos (2013); à leitura desconstrutiva, Opitz (2012); ̀̀ crítica do direito pós-colonial, Gonçalves (2013b).

2. No jornal Taz, já em 14 de janeiro de 2008, escreveu-se acerca de "luhmannianos de esquerda" (Körner, 2008); a esse respeito, conferir também o projeto programático de uma teoria crítica dos sistemas (Fischer-Lescano, 2009) e a intermediação entre a teoria da evolução sociológico-sistêmica e a teoria da evolução marxista (Brunkhorst, 2014). 
entre racionalidade própria e autonomização do direito: por um lado, a forma de direito existente é criticada, juntamente com seu potencial de autonomização de poder; por outro, a racionalidade própria do direito é designada como ponto de partida digno de defesa para uma crítica da sociedade.

Primeiramente, gostaria de mostrar que na doutrina crítica do direito do contexto da primeira geração da Escola de Frankfurt aquela aporia já está colocada. Ela critica o direito em nome da sociedade. Permanece comprometida com o ideal marxista de uma "associação de homens livres" (Marx, [1864] 1972, p. 92), na qual um sistema jurídico diferenciado é renunciável. Essa posição, porém, entrelaça-se imediatamente com um movimento crítico que parte do conceito de direito. De acordo com tal movimento, a sociedade capitalista fracassa na realização dos excedentes normativos do ideal de direito burguês anterior. Desse modo, o direito aparece em uma meia-luz peculiar. É objeto $e$ ponto de partida da crítica (I).

Esta relação de tensão aporética emerge novamente na crítica jurídica da primeira teoria sistêmica. Aqui ela é, contudo, consideravelmente deslocada, pois a diferenciação funcional substitui os fundamentos político-econômicos. A perspectiva da teoria comunicativa não une, obrigatoriamente, o direito ao Estado ou às relações de circulação econômica, mas posiciona o sistema jurídico em uma cadeia recursiva de comunicação jurídica que se orienta por meio do código lícito/ilícito. Porém, como mostrarei em um segundo passo, a nova crítica do direito aflui em uma aporia similar (II). O sistema do direito funcionalmente diferenciado também indica um potencial de violência e alienação. No transcurso de uma maximização problemática da própria racionalidade, o direito isola-se do seu ambiente. Também a nova crítica jurídica introduz a ideia de um direito autônomo, autorreferencial, para criticar a intrusão de tendências de controle políticas ou econômicas externas. Novamente, tudo aflui em uma aporia. A nova crítica jurídica submete o direito a uma crítica radical e, na mesma medida, alça sua racionalidade própria a uma porta de entrada para uma crítica mais abrangente da sociedade. Ela critica o direito em nome da sociedade e critica a sociedade em nome do direito.

Assim, fórmulas alternativas atuais como responsividade, transcendência ou estetização do direito podem ser lidas como estratégias para desenvolver esta aporia (III). Neste passo, torna-se claro não apenas como pode ser produtivo suportar a aporia e não a dissolver de maneira jurídico-conservadora ou jurídico-niilista. Também se destaca que a nova crítica do direito depende de uma sensível revisão de análise de poder de seus fundamentos - ou nas palavras de Adorno: 
[...] que a teoria hoje é transposta na difícil situação de ser tanto sistema como não sistema: sistema na medida em que deve expressar a unidade da sociedade [...], de outro lado, porém, também não sistema na medida em que, como foi mostrado, esta unidade, por seu turno, é ela própria produzida por antagonismos, foi mostrado também que essa unidade mesma em seu absoluto produziu de si a desunião (Adorno, 2008, p. 125).

\section{Doutrina crítica do Estado de direito}

A doutrina crítica do Estado de direito, que desde os anos de 1920 e 1930 tem êxitos no campo da primeira geração da Escola de Frankfurt, é designada por uma aporia peculiar. Caso se submeta este ramo de discussão a uma observação conjunta, destaca-se de imediato uma relação de tensão: o direito da sociedade burguesa é criticado e, ao mesmo tempo, valorizado. No núcleo dessa discussão, autores como Franz L. Neumann ou Otto Kirchheimer lançam mão de uma posição que segue a linha da tradição marxista. Desse modo, a sociedade capitalista burguesa só é pensável em conjunto com uma forma de direito autonomizada. Isto vale, sobretudo, em relação ao mercado capitalista e suas relações contratuais. Ele é fundamentalmente dependente de um sistema jurídico. Além disso, o direito modela os participantes do mercado como sujeitos livres e iguais, que regulam juridicamente suas trocas com abstração das desigualdades sociais ${ }^{3}$. Assim, ele contribui para a estabilização ideológica do mercado capitalista: ocupa-se da subjetivação e da coesão (Buckel, 2007).

Porém, na tradição marxista, a observação não se estende apenas para o direito privado, mas também para o direito público. Nessa linha, existe a suposição de que o Estado não se opõe simplesmente às relações de circulação econômicas; antes, o aparelho de Estado ocupa-se, como "capitalista coletivo ideal", de uma coordenação de interesses no interior das classes burguesas (Engels, [1877] 1962, p. 260). O direito aparece aqui, sobretudo, como estabilizador, sustentando as relações de classe existentes e mantendo os dominados em estado de passividade. Com sua cultura de expertise e seu modo de proceder fortemente subjetivista, ele distorce as linhas de conflito social. A partir desse ponto de vista, o sistema jurídico como parceiro de diálogo para os anseios crítico-sociais está praticamente fora de questão. Já Karl Marx tinha indicado as barreiras que o direito moderno constitui para a emancipação em constatações isoladas sobre a crítica do "horizonte jurídico burguês" (Marx, [1875] 1962, p. 21; [1843] 1972).

A doutrina crítica do direito permanece comprometida com essa herança; contudo, vai por outros caminhos, que, em última instância, evocam a men-
3. A teoria do direito marxista de Paschukanis (2003) vai mais além na leitura político-econômica do direito moderno, na medida em que configura uma "homologia" entre a forma mercadoria e a forma direito. 
cionada aporia. Ela é colocada especialmente na obra do teórico do direito Franz L. Neumann. Nas suas reflexões em $A$ mudança de função da lei no direito da sociedade burguesa, de 1937, Neumann traça uma história do declínio do direito (Neumann, 1967). Primeiramente - e aqui ainda em completa ressonância com a linha de tradição marxista -, ele caracteriza o sistema jurídico moderno. Neumann analisa sua função protetora para as relações de circulação econômica destacando sua função de dissimulação ideológica (Neumann, 1967 , p. 26; 1980, p. 246). Contudo, ele dá a essa observação uma alteração decisiva quando identifica o direito moderno com a precedência da lei geral e universal: "A livre concorrência necessita da lei geral e universal, porque é a forma mais acabada da racionalidade formal; deve, simultaneamente, exigir também a subordinação absoluta do juiz à lei e, com isto, à divisão de poderes" (Neumann, [1937] 1967, p. 24).

O modelo inicial burguês indicado aqui parte do pressuposto de que a livre concorrência do mercado capitalista depende de um tipo de racionalidade formal. A calculabilidade requerida do direito pode ser produzida apenas de modo que a classe burguesa crie no parlamento uma representatividade por meio da qual ela determina leis que devem preservar, em troca, o critério da universalidade. Elas devem, ainda, ser determinadas no conteúdo e praticamente não deixarà justiça um espaço de interpretação para a aplicação do direito. No entendimento de Neumann do direito moderno há apenas uma abertura unilateral para a legislação parlamentar, ao passo que, com relação aos outros meios sociais, há um fechamento radical. No sistema jurídico há apenas subsunção, compreensão esta que advém, para Neumann, de uma situação na qual a "estrutura formal” de tal sistema corresponde à "estrutura material” de um capitalismo concorrencial de mercado livre (Idem, p. 31).

Conforme Neumann, ocorre, contudo, um processo de mudança. O capitalismo monopolista dissolve a livre concorrência. Da forma de negociação do contrato, os participantes do mercado passam a coordenar-se e conectar-se em monopólios (Idem, pp. 31 e ss.). Estado e direito perdem novamente seus papéis distanciados, ao menos formalmente, dos processos econômicos de troca. Eles intervêm diretamente na vida econômica. Desse modo, o ideal de direito burguês anterior subjuga a si mesmo. No capitalismo monopolista, sua racionalidade é destruída. No lugar de um código legal, entra um aparato judicial progressivamente autonomizado, que é cunhado por amplo espaço de discricionariedade. Neumann ilustra esse desenvolvimento na República de Weimar. A promessa de uma democracia social da constituição de Weimar é conduzida progressivamente, com o passar dos anos, a uma privação em 
massa de direitos, ao fim da qual está o controle direto de grupos autoritários de poder. Com o fortalecimento do papel de cláusulas gerais surgem amplos espaços de indeterminação na aplicação do direito (Idem, pp. 39 e ss.). Elas levam, via de regra, a que as relaçôes de poder sociais - já existentes, de todo modo - traduzam-se facilmente em direito, sem antes ao menos ter de passar pelo estabilizador da legislação. Portanto, esta é a consequência do diagnóstico de declínio de Neumann: com a racionalidade formal desaparece também o "mínimo de liberdade" no direito (Idem, p. 51). Tanto o direito se comporta funcionalmente para as relações de poder capitalista, como, ao mesmo tempo, impede o controle direto dos interesses de poder com suas exigências de determinação e universalização. Contudo, esse mínimo de liberdade recai na mudança funcional da lei. No lugar do direito, entra um direito que não merece mais o nome, porque não é determinado de modo universal, nem no conteúdo.

A observação de Neumann é de interesse para nossos objetivos sobretudo porque aqui se desenha uma crítica do direito que não é uma crítica simples ao direito. É uma crítica ao direito em nome do direito, ou, mais claramente, a uma privação fatual de direitos, que vem apenas sob o manto da juridificação da sociedade industrial moderna. Por isso é possível, com base na leitura da tese de declínio de Neumann, mostrar sempre como a sociedade moderna mina seu mito fundante, qual seja, produzir uma auto-organização dos burgueses livres e iguais em meio a uma lei geral e universal. A teórica frankfurtiana do direito, Ingeborg Maus, aderiu às reflexões de Neumann exatamente neste sentido. Ao aplicar as teorias iniciais do direito burguês de Rousseau e Kant, ela mostra como o "direito" da sociedade industrial moderna corresponde nos mínimos detalhes a determinada ideia jurídica (Maus, 1992). Portanto, o "potencial não satisfeito de uma sociedade futura, auto-organizada” (Buckel, 2011, p. 34), já está colocado no conceito de direito.

Para nossa questão condutora - a relação de doutrina crítica do Estado de direito e a teoria dos sistemas -, é sobretudo interessante que Neumann veja o mínimo liberal na pretensão de universalidade da lei jurídica e seu fechamento contra a sociedade. Justamente o fechamento do sistema jurídico, com abertura unilateral para o sistema político, é a garantia. A crítica da doutrina do direito no contexto da primeira geração da Escola de Frankfurt aflui, portanto, em uma aporia: ela permanece em muitos aspectos crítica jurídica em sentido forte, na medida em que, em nome de uma sociedade justa, coloca fundamentalmente em questão o direito burguês. Contudo, ela critica o capitalismo moderno e seu direito da mesma maneira em nome do 
4. É interessante o fato de que esses esforços já tinham, então, uma dimensão sociomundial (Saavedra, 2014). conceito de direito. Ao reconduzir a autorreferência jurídica para seu caráter dominador, defende o direito como mecanismo de subsunção doutrinária.

À luz desta aporia entre autonomização e racionalidade própria do direito aparece uma sequência de fórmulas alternativas. A perspectiva, por exemplo, de Otto Kirchheimer de uma politização do direito, que conduz o momento político do conflito social ao direito, pode ser lida como tentativa de navegar entre esses polos (Kirchheimer, 1976). O mesmo vale para os esforços influentes de alimentar um direito não liberal com direitos fundamentais ou com uma constituição trabalhista, e a partir daí efetuar uma transformação da sociedade.

\footnotetext{
Se não sucedeu aos trabalhadores transformar fundamentalmente a economia e a sociedade existentes por meio do avanço da revolução, eles estiveram, contudo, em condições de desviar uma reforma da ordem do Estado e da sociedade [...] nas águas navegáveis sociopolíticas e de direito do trabalho [...]. Característico disso é o desenvolvimento da constituição referendária, que foi comutada do terreno político para o socioeconômico, falhou política e economicamente, mas, ao menos em parte, manteve-se em funcionamento na figura dos conselhos empresariais (Fraenkel, 1973, p. 65) ${ }^{4}$.
}

Nesta fórmula alternativa do direito social são, de fato, lançados a bordo os dois polos extremos da crítica do direito. Contra a crítica categórica do direito, aposta-se na juridificação como instrumento político; contra a crítica da sociedade cunhada por Neumann em nome do ideal inicial de direito burguês é apontada uma compreensão do direito não liberal totalmente diferente. Apesar disso, apenas a tensão constituída prepara o chão frutífero para essa fórmula alternativa, na qual o direito não é elevado nem à máquina emancipatória nem simplesmente a instrumento de dominação.

\section{Crítica luhmanniana de esquerda do direito}

$\mathrm{Na}$ crítica contemporânea do direito, designada no início do texto como luhmannianismo de esquerda, emerge novamente a aporia da doutrina crítica do Estado de direito. Ela é reorientada consideravelmente, pois o ponto de referência não é a sociedade capitalista burguesa, mas a diferenciação dos diversos sistemas sociais, conforme Niklas Luhmann pressupôs em sua teoria dos sistemas. Aqui também encontramos a tensão entre autonomização e racionalidade própria do direito e, com isso, estamos entre dois momentos da crítica jurídica, que abrem o espaço para uma sequência de fórmulas alternativas atuais, como, por exemplo, transcendência ou estetização do direito. 
Em primeiro lugar, é naturalmente necessário fundamentar como é possível que a contemplação teórico-sistêmica avance para o ponto de partida de uma crítica do direito. Isso pode ser explicado decisivamente por duas mudanças de posição. Com relação ao impulso expansivo do sistema, assim como aos paradoxos fundamentais e de aplicação no direito, ocorre uma transcrição da teoria ortodoxa dos sistemas. Apenas essa transcrição conduz, a cada passo, a uma tensão entre a crítica jurídica em nome do ambiente social e a crítica da diferenciação funcional em nome do direito.

\section{Impulso expansivo e colonização}

O primeiro deslocamento do luhmannianismo de esquerda consiste em que o impulso expansivo do sistema social é alçado a problema. Os sistemas aparecem como formas autonomizadas. Eles separam-se do ambiente social e isolam-se de influências externas. Ao enorme potencial de desenvolvimento da diferenciação funcional estão inerentes alguns inconvenientes. Os sistemas intensificam regularmente as próprias funções em detrimento de seus ambientes sociais. Desse modo, liberam "tendências imperialistas" (Teubner, 2006, p. 174). Essa observação sobre a maximização da racionalidade própria é certamente menos derivada da teoria dos sistemas de Luhmann do que da crítica marxista da economia política. As forças produtivas da evolução social tornam-se forças destrutivas.

Com relação ao direito, esse processo leva a que a intervenção colonizadora de outros sistemas seja problematizada. A nova crítica jurídica demonstra em uma sequência de estudos que, na transição para a sociedade mundial, outros sistemas sociais servem-se crescentemente do código jurídico. Isso vale onde o sistema funcional econômico introduz o direito apenas de modo instrumental e, assim, não pode gerar estabilização de expectativas normativas (Renner, 2011a) ou lá onde o código de poder político simplesmente se propaga para o direito. Aqui o direito está, é certo, no papel, mas permanece subordinado ao código de poder. Alopoiese no lugar de autopoiesis (Neves, 2001). A crítica jurídica da teoria dos sistemas repousa sobre a autonomia do direito. Ela rejeita rigorosamente tendências de controle externo. $\mathrm{O}$ objetivo consiste em uma manutenção da liberdade do código. De maneira quase neumanniana é exposta aqui uma crítica do direito (existente) em nome de um sistema jurídico diferenciado funcionalmente, com a diferença de que as tendências de controle externo não procedem apenas da economia capitalista, mas podem provir também de outros sistemas funcionais. 
5. O ponto de fuga consiste em uma colisão jurídica, que toma empréstimos da teoria procedural do direito de Rudolf Wiethölter (2005).

6. As contribuiçōes para a questão da constituição na nova crítica do direito investigam, por isso, a autorrestrição no meio de uma ordem jurídica hierarquicamente mais elevada (Fischer-Lescano, 2005; Holmes, 2013; Möller, 2014; Renner, 2011b; Teubner, 2012).
Esse elogio à autorreferência jurídica está diretamente ligado a uma outra variante crítica. A colonização não precisa transcorrer obrigatoriamente de outros sistemas funcionais para o direito. $\mathrm{O}$ caminho inverso deve ser igualmente considerado. O próprio sistema jurídico pode colonizar seu ambiente social, na medida em que transmuta tudo em uma questão jurídica. Ele transforma consideravelmente condições de conflito e condições de colisão social e frequentemente as deforma até o irreconhecível (Amstutz, 2013). Aqui a nova crítica do direito da teoria dos sistemas pede cautela. $\mathrm{O}$ direito não está em condições de governar a partir de cima ou mesmo de resolver conflitos. Ele pode, no máximo, criar compatibilidades, conectar sistemas funcionais e, em longo prazo, apresentar a conflitos sociais o custo de suas distorções jurídicas $^{5}$. Nessa leitura, os ambientes sociais recebem um papel forte, inteiramente normativo, pois são ameaçados pela maximização sistêmica da racionalidade própria. São, portanto, aqueles lugares a partir dos quais pode advir a pressão que, consequentemente, conduz a autorrestrições dos sistemas funcionais (Francot-Timmermans e Christodoulidis, 2011) ${ }^{6}$.

Se na primeira orientação estava em ação uma crítica da sociedade (alopoiética) em nome do direito, então na segunda orientação, por sua vez, deve ser divisada uma crítica do direito em nome da sociedade. Isso vale, sobretudo, para aqueles ambientes sociais que aparecem à luz de um mundo da vida que necessita de proteção. A sociedade diferenciada funcionalmente se torna um ideal inteiramente normativo da "liberdade da sociedade civil" (Teubner, 2000, p. 488), no qual as condições existentes são mensuradas.

\section{Paradoxos}

A nova crítica também toma uma guinada luhmanniana de esquerda em relação aos paradoxos especificamente sistêmicos, uma vez que nos limites entre direito e ambientes sociais não se realizam exclusivamente colonizações. Aqui está estabelecido, na mesma medida, um potencial reflexivo que, no caminho de uma re-entry da distinção sistema/ambiente, pode entrar na lógica funcional (Luhmann, 1993b). Estes são aqueles momentos de abertura que ascendem a portas de entrada para possíveis correções. A autorreferência interrompe-se e, no interior do sistema, isso pode se refletir em seus limites. A re-entry da distinção sistema/ambiente cria espaço para que as racionalidades do ambiente possam ser reconstruídas e consideradas de maneira intrassistêmica (Teubner, 2012, p. 158). Este é o caso, por exemplo, quando desafios e protestos interrompem a "conversa" sistêmica "consigo mesmo". 
As condições de possibilidade desta re-entry da distinção na distinção tornam-se possíveis porque os sistemas funcionais se baseiam em terreno precário. Eles não possuem fundamentos fixos. Os sistemas funcionais são transpassados por paradoxos, que se fazem notar como indeterminações e indiferenciações (Luhmann, 1984, p. 641). Quando a relação de autorreferência exitosa e de precariedade comunicativa é iluminada mais de perto, depara-se com a forma dos paradoxos. Esta forma é uma relação de conflito especialmente exigente, que deve ser diferenciada de contradiçóes simples. Os paradoxos têm a forma "A, porque não A", enquanto as contradições seguem o modelo "A - não A". Os paradoxos deixam-se definir da seguinte forma: eles relacionam possibilidade e impossibilidade. Eles aparecerem, portanto, quando as condições de possibilidade de uma operação expõem, ao mesmo tempo, suas condições de impossibilidade.

Os paradoxos movem-se, então, sobre dois níveis da autorreferência jurídica (Stäheli, 1998, pp. 58 e ss.). E, com efeito, em primeiro lugar, como paradoxo fundamental da distinção sistema/ambiente. Para fixar-se, a identidade do sistema funcional deve se relacionar com o ambiente social. Com isso, ela não é totalmente independente e fechada, mas também dependente do ambiente e, de certo modo, aberta. A autorreferência é possível (porque fechada operativamente) e, contudo, sempre impossível (porque dependente do ambiente). Em segundo lugar, o paradoxo é visível como paradoxo de aplicação, pois cada sistema pode expor o código próprio de dois valores mais uma vez à observação. A distinção lícito/ilícito pode ser submetida outra vez a uma distinção lícito/ilícito; o lícito pode ser observado como ilícito e vice-versa. Para não cair em um regresso infinito de autoquestionamento, o sistema funcional cultiva técnicas próprias de “desparadoxização". Ele reprime essas incertezas em seu próprio operar. Isso funciona, contudo, sempre provisoriamente, pois o paradoxo pode aparecer sempre novamente e oferecer oportunidade para uma correção de autorreferência ${ }^{7}$.

Ainda que a versão ortodoxa da teoria dos sistemas já tivesse essa estrutura fundamental em vista, a orientação luhmanniana de esquerda leva o paradoxo a uma contradição real (Fischer-Lescano, 2009, p. 56). No impulso de expansão dos sistemas funcionais e suas técnicas de desparadoxização é dada, sob a mesma base de origem, a possibilidade da reparadoxização. A re-entry da distinção sistema/ambiente abre espaço para o reflexo na respectiva (não) identidade específica do sistema funcional e pode levar a autolimitações.

Como consequência, o paradoxo recebe um status alterado. Na teoria dos sistemas ortodoxa, "o sistema utiliza o paradoxo para se desparadoxizar
7. Sobra a relação entre reparadoxização e desparadoxização no sistema do direito por meio da figura da segurança jurídica, ver Gonçalves (2013a). 
mediante uma compulsão à diferenciação assimétrica e para possibilitar seu desenvolvimento como sistema" (Blecher, 1991, p. 55). Lá, a possibilidade de reparadoxização certifica os esforços necessários para se adaptar às condições ambientais alteradas. $\mathrm{Na}$ orientação do luhmannianismo de esquerda, ao contrário, o paradoxo não encerra apenas os potenciais de aprendizagem de adaptação cognitiva, mas também normativa. Na medida em que a autorreferência é interrompida, surgem processos reflexivos e uma permeabilidade entre sistema e ambiente.

Esta revalorização do paradoxo aflui no sistema jurídico outra vez na relação de tensão que indicamos. O paradoxo jurídico fundamental (a fixação da distinção lícito/ilícito) é interrogado em seu caráter pleno de violência. Em correspondência com observações de autores como Jacques Derrida ou Walter Benjamin, a nova crítica sustenta que direito e violência são entrelaçados um ao outro de maneira inseparável (Derrida, 1991; Benjamin, [1921] 1991; Fischer-Lescano, 2013a; Menke, 2013b; 2014). Logo, o direito repousa na base de uma violência fundamental ilícita, a qual ele não perdeu completamente nos strange loops comunicativos. A autorreferência jurídica, que fixa a si própria na distinção com o ilícito, permanece marcada por relações de violência. No nível do paradoxo de aplicação emerge então um nexo "político". A possibilidade de encontrar a distinção entre lícito e ilícito outra vez ou de questioná-la em relação à justiça do direito como uma fórmula de contingência sistêmica interna (Luhmann, 1993a, pp. 218 e ss.) adjudica ao sistema jurídico grande espaço durante a aplicação e a interpretação jurídicas. Nesse sentido, uma política do direito pode ser observada no direito. Aqui, luta-se politicamente por hegemonia jurídica (Buckel, 2007, pp. 221 e ss.; Liste, 2012). Novamente, nos dois níveis do paradoxo, tal crítica encontra sua defesa: de um lado, o direito está preso a uma violência fundamental; de outro, ele reserva o terreno para disputas que o rebaixa a um instrumento político.

Contudo, ao lado dessa forma de contemplação analítica de poder está uma forma normativa. A nova crítica destaca igualmente que o direito pode trabalhar ambos os problemas - violência e politização. Com seu espaço para a "proceduralização" e sua orientação na justiça como fórmula de contingência “desparadoxizadora”, ele pode tematizar a base plena de violência e, até mesmo, superá-la (com respeito a isso, ver mais adiante). Ao menos parece possível confrontar o direito injusto com um outro, o direito justo. Nisso, o sistema jurídico funcionalmente diferenciado coloca tentativas de politização sob uma pressão à comunicação especificamente jurídica, de tal maneira que - ao menos em um modo de ver ideal - interesses nunca podem simplesmente 
representar-se de modo jurídico, mas devem ser, de certo modo, civilizados no discurso jurídico. O direito torna-se um gentle civiliser ${ }^{8}$.

Para resumir, devemos também nos deter ao fato de que a crítica luhmanniana do direito conecta-se inteiramente ao campo de problema da doutrina do Estado de direito. Ela destaca o potencial de violência, alienação e autonomização. Os ambientes sociais apontados quase romanticamente são, então, o ponto de partida para uma crítica do sistema social em expansão. Essa variante crítica associa-se com o ideal de um sistema jurídico diferenciado. Aqui os modos internos dos processos e as técnicas de comunicação do direito valem como portadores de esperança contra uma des-diferenciação nociva à liberdade.

\section{Fórmulas alternativas}

Se da aporia da crítica do direito já tinham resultado no campo da primeira geração da Escola de Frankfurt diferentes fórmulas alternativas, também nas reflexões teórico-sistêmicas emergem movimentos de pensamento emoldurados de maneira similar. No trânsito entre três fórmulas alternativas atuais - responsividade, transcendência e estetização do direito -, fica claro não apenas a necessidade de suportar a estrutura aporética da crítica do direito ${ }^{9}$, como também surge um amplo déficit, a saber: a nova crítica jurídica propôs uma abertura normativa sem circunscrever os correspondentes pressupostos teórico-sociais básicos. Apenas quando a teoria da diferenciação funcional experimenta uma revisão de análise de poder pode ser indicado em que sentido um outro direito não duplica simplesmente as relações sociais existentes.

\section{Direito responsivo}

A primeira fórmula alternativa que cresce da crítica aporética do direito é a exigência de responsividade. Este é o núcleo de toda uma sequência de contribuições para o direito transnacional ou para a função dos direitos humanos (Renner, 2011b; Teubner, 2006; Viellechner, 2013). O “pecado original” da diferenciação funcional não deve ser revertido ${ }^{10}$. Também uma subordinação hierárquica do sistema jurídico ao processo de legislação política, avistada por Neumann, não é mais apreciável na sociedade mundial funcionalmente diferenciada - e essa sociedade também está sujeita ao perigo de um controle político externo. A fórmula alternativa "direito responsivo" é utilizada para trabalhar o problema fundamental da colonização recíproca nessas condições. A re-entry da distinção sistema/ambiente no sistema cria o
8. Martti Koskenniemi (2002) descreve dessa forma o papel do direito internacional.

9. E isso especialmente em oposição a uma defesa meramente conservadora do direito ou sua simples rejeição.

10. Esta é a formulação clássica de Luhmann (1994, p. 344).

novembro 2015 
espaço de possibilidade para que o direito se abra para os ambientes sociais. Oportunidades procedurais de participação de atores da sociedade civil, considerações interno-legais obrigatórias e regras de coordenação devem impedir uma autonomização do sistema jurídico. Homens e direitos fundamentais não são, neste modo de ver, superpadrões morais. Devem ser entendidos como portas de acesso para representar reivindicações do ambiente social - seja dos indivíduos, seja dos discursos sociais - no direito e, assim, mantê-lo também "responsivo". Apesar disso, o sistema jurídico permanece naturalmente conservado. $\mathrm{O}$ direto responsivo não deve conduzir a que a lógica jurídica seja simplesmente instrumentalizada por outros discursos. Ao contrário, conflitos sociais devem ser traduzidos em quaestio iuris. Lá devem ser reformulados no campo de um formalismo jurídico e de suas exigências de consistência. Neste nexo, poder-se-ia, de fato, falar em uma política interna do direito no direito (Horst, 2013). Contudo, ela nunca chega ao núcleo da diferenciação funcional: não pode chegar, porque a nova crítica jurídica - com Luhmann - parte do pecado original irreversível da diferenciação funcional. E tal crítica não a pode colocar em questão, porque, do contrário, há a ameaça de um controle externo nocivo à liberdade.

No contexto de uma responsividade assim compreendida, evidencia-se ao menos uma objeção, que se orienta nas reflexões da doutrina crítica do Estado de direito. Se o sistema jurídico moderno estabiliza expectativas normativas e está em relações de acoplamento com outros sistemas sociais, uma perspectiva crítica deveria sempre deixar espaço para revogar modelos de diferenciação evolucionários. Afinal, o decurso da diferenciação funcional efetivado até aqui não pode ser reduzido apenas à evolução, mas também deve se considerar que ele somente foi consumado por meio de mudanças revolucionárias (Berman, 1991; Brunkhorst, 2014) - com todos os seus epifenômenos des-diferenciadores, político-instrumentais, de retrocesso romântico e de avanço messiânico. Justamente as "grandes inovações na constituição jurídica da sociedade moderna" não "são consequências de adaptação gradativa, mas o resultado de revoluções políticas. Sobretudo nas grandes revoluções jurídicas, processos de aprendizagem normativos, que foram desencadeados por meio de conflitos estruturais de classe [...], consolidaram-se em ações institucionais fundamentais e extensas reformas sociais" (Brunkhorst, 2011, p. 322). Uma perspectiva crítica do direito também precisa de um momento de reflexão sobre a totalidade, caso contrário, tende a reificar de maneira completamente precipitada a diferenciação funcional. E em uma sequência grande de desenvolvimentos de nossa contemporaneidade, por exemplo em relação à juridificação do mercado 
financeiro internacional, o caminho da pretensão crítica é facilitado, caso ela se ocupe em manter o direito o mais aberto possível.

Essa leitura reificadora da diferenciação funcional conduz, desse modo, a um outro ônus da prova. Aqui, a crítica neumanniana vale-se da abertura do direito: a responsividade jurídica não conduz, simplesmente, à duplicação das relações existentes no direito? Ela não ocasiona que, nas condições de um discurso jurídico especializado com seus caminhos de acesso restritos e seu recrutamento elitista, ao final, sejam levados em conta os interesses dos grupos de poder mais fortes? O mínimo ético contido em um discurso de direito fechado, insensível a pressões, seria solapado. Em todo caso, seria necessário mostrar como deve ser evitada a circunstância que simplesmente subscreve outra vez as relações de poder sociais no direito ${ }^{11}$.

\section{Transcendência do direito}

Reflexões recentes sobre transcendência do direito tomam aqui um caminho mais radical. Elas conectam a observação de modo muito mais forte com pressupostos da desconstrução e da teoria crítica, o que leva a uma via de argumentação configurada de maneira bastante complexa e acentua outra dimensão. Não se trata mais de um mero cerco da diferenciação funcional, mas de uma perspectiva que transcende, que aflui em um direito totalmente diferente: "Assim compreendida, a exigência de justiça visa a um direito novo, diferente e ao estabelecimento de uma ordem humanamente digna; um direito mimético, no qual a justiça possa ser mantida em movimento" (Fischer-Lescano, 2013b, p. 61).

O movimento de transcendência do direito começa com a crítica à violência jurídica. De acordo com esse movimento, o direito leva em seu bojo um maciço potencial de violência, em vez de meramente suprimir de modo unilateral relações de violência ou apenas moderar conflitos sociais na órbita legal. A violência jurídica é primeiramente construída no momento do paradoxo fundamental do direito, o qual é colocado em relação com o ambiente não jurídico. Trata-se de um processo que, como mostra Jacques Derrida em sua crítica jurídica, contém ele mesmo um momento ilícito, ilegítimo, uma razão mística (Derrida, 1991). Esta violência prossegue. O direito não se separa dela. Ele impõe aos ambientes sociais suas leis inerentes, seu estilo argumentativo, seus procedimentos. E nele mesmo permanece conservada uma dimensão "decisionista" em seu caráter frequentemente indeterminado e carente de concretização. Além disso, a nova crítica chama a atenção para a associação do direito com outras relações sociais de poder:
11. Em concordância com a observação de Ingeborg Maus (1986, p. 255), segundo a qual a teoria moderna do direito simplesmente duplica a base social. 
12. Conferir em Fischer-Lescano e Möller (2012) os exemplos a respeito do direito transnacional.

13. Femia (2013) descobre até mesmo os espaços de possibilidade para uma "subversão infrassistêmica".
A potência violenta do direito é mais fundamental, mais abrangente, mais sutil: o direito fundamenta, distribui, restringe competências políticas e potencialidades econômicas. Ele constitui violências privadas e públicas. Ele e seus mecanismos de sanção, que oferecem proteções simbólicas nos casos de expectativas legais frustradas, estão enlaçados nas relações sociais de violência (Fischer-Lescano, 2013b, p. 33).

Com isso, o campo de visão direciona-se para as ligações recíprocas de relações violentas jurídicas e sociais. Frequentemente, o direito não constitui o antídoto, mas antes torna essas ligações possíveis ${ }^{12}$.

A agudeza da nova crítica do direito consiste em que ela divisa forças antagonistas sobre os dois lados: o do direito e o dos ambientes sociais. Do lado jurídico, tal força é, sobretudo, a justiça. Dado que "nada no direito é excluído da expectativa” de ser “justo” (Idem, p. 26), então, no direito, não apenas a força plena de violência do direito existente que é operativa. A pretensão de decidir consistentemente e de maneira justa introduz um espinho, uma força antagonista, que mede o direito na escala do direito justo. Niklas Luhmann indicou esse espinho quando alçou a justiça à fórmula contingente do sistema jurídico (Luhmann, 1993a, pp. 218 e ss.). Enquanto em Luhmann a justiça é mero instrumento que possibilita que a decisão consistente sob condições ambientais alteradas siga adiante, ela torna-se aqui uma fórmula de transcendência subversiva (Teubner, 2008 $)^{13}$. A estrutura fundamental do sistema do direito contém uma força que possibilita colocar em questão as relações de violência jurídicas e sociais do ponto de vista de um direito justo - uma crítica da sociedade em nome do direito.

A reivindicação de uma transcendência jurídica contém também a direção crítica inversa. Ela critica o direito em nome da sociedade. Assim, os padrões jurídicos de racionalidade comprimem a vida humana em um corpete estreito, em especial suas forças a-racionais, que, muitas vezes, não dispõem de uma linguagem. Essa "pluralidade de forças vitais” subjugadas é, então, novamente o ponto de conexão para a crítica do direito (Fischer-Lescano, 2013b, p. 106).

A transcendência apenas se torna pensável porque ambas as forças antagônicas - a justiça no direito e os afetos subjugados da vida - são distinguidas. E ambas as forças devem ser conectadas entre si. A força da justiça no direito é ativada pelo fato de que as forças subjugadas da vida começam a assimilar-se ao direito e a levar o conflito para seu interior; o direito é então desvinculado de sua ligação com relações de violência estatais e econômicas. No sentido de um direito à força, o direito deve apenas se preocupar com a possibilidade de a pluralidade de forças subjugadas se desenvolver. O ponto de fuga é outro direito, que deveria existir sem violência, Estado e poder econômico. 
O problema é que até agora essa perspectiva não conseguiu identificar como o outro direito pode vir a se tornar uma possibilidade real. A assunção do teorema luhmanniano de diferenciação é responsável por não ser possível diferenciar efetivamente entre forças dominantes e subjugadas. O húmus sobre o qual a busca por justiça no direito deve crescer permanece no ponto cego, o que fica evidente quando essa posição é relacionada com as fórmulas alternativas da doutrina crítica do Estado de direito. O direito social nela reclamado podia amparar-se em uma imposição coercitiva aprovada no contexto do Estado para afirmar-se contra o direito liberal ou ainda mobilizar respaldos sociopolíticos por meio de sindicatos e partidos, que, por via das dúvidas, também tinham o potencial violento (!) oferecido pela greve para ajudá-lo a legitimar-se. A reivindicação de um direito justo e a arrogância do sistema contra as forças da vida a-racionais ainda existem. Apenas quando essas forças puderem também tornar válido um potencial de poder, elas se tornarão violência material (!) na evolução social. Libertar as forças sociais da violência, sem violência, é algo inquestionavelmente coberto por abundantes referencias na história das ideias. Elas se estendem do anarquismo à tradição judia de direito (Loick, 2012), porém devem ser submetidas à recriminação do dom-quixotismo. Rosa Luxemburgo aguçou isso polemicamente:

Pois chegamos felizes ao princípio da justiça, a este antigo curso, desde séculos galopado por melhoradores do mundo na falta de meios de transporte históricos mais seguros, a este Rocinante frágil, sobre o qual todos os Dons Quixotes da história cavalgam para grandes reformas do mundo, para, finalmente, não trazerem de volta nada mais do que um olho azul (Luxemburg, 1966, p. 106).

\section{Estetização do direito}

Por fim, a estetização do direito possui papel central na nova crítica jurídica. Este é justamente aquele ponto de partida que solapa de maneira mais forte a diferenciação funcional. Se em relação à transcendência a questão era ainda a de uma outra forma de direito, aqui a autonomização do sistema é problematizada de maneira mais detida. Em um primeiro exame, é frequentemente difícil compreender o que é imaginado com estetização. Seria a reflexão do direito no meio da arte algo como a linha de pesquisa direito e literatura ou direito e música (Manderson, 2014)? Seria a estética mesma do direito sua dimensão experimentável também de modo sensório, que vai da configuração dos atos a um tipo de "gosto" nas decisões legais (Koskenniemi, 2005, p. 123)? Inquestionavelmente, 
14. Sobre o entrelace entre direito e estética haveria certamente muito mais coisas importantes a dizer. Em especial, a relação entre direito e música está aqui gradativamente no centro (Manderson, 2013; Tetzlaff, 2004). Para mim trata-se, contudo, de ilustrar de que forma a estetização do direito desemboca em uma crítica à forma jurídica e não apenas estimula um modo de observação mais abrangente dentro do discurso científico do direito. ambos os campos mencionados são significativos para uma reflexão sobre os princípios do sistema do direito moderno. A conexão com uma crítica jurídica efetiva permanece ainda muito vaga ${ }^{14}$. Por outro lado, na nova crítica jurídica, duas compreensões de estetização em andamento relacionam-se, sobretudo, para estabelecer um contato com as forças subjugadas.

Nesse sentido, a nova reflexão jurídica passa a uma crítica fundamental da razão. De acordo com ela, a cultura jurídica constituída linguisticamente isola-se completamente dos movimentos e dos afetos do ambiente social. Tais afetos, que não se deixam traduzir na comunicação jurídica, aparecem no sistema do direito como mero ruído. Desse modo, surge uma consequente incapacidade de empatia do direito, que socava sua justiça: "apenas sob a premissa da capacidade de empatia, contudo, as ficções jurídicas presas aos limites da razão e as decisões que nela se baseiam são suportáveis" (Hensel, 2013, p. 84). A sugestão é escutar mais precisamente a decodificação do ruído: o ruído exige do direito que se configure nele o "espaço imaginário" por meio do acoplamento ao sistema de percepção "ouvido" como "corpo de ressonância" (Idem, p. 85). Para ativar as forças da justiça no direito são necessários corpos de ressonância como o ouvido e sua escuta: "A reformulação dos resultados de percepção é possível apenas na forma da linguagem jurídica e nas seleções nela expostas. Contudo, com o foco no escutar, o outro da linguagem pode se efetivar no discurso jurídico; ruídos, vibrações, tônicas são interrogados, o direito não pode mais ignorá-los" (Idem, p. 88). Nesse sentido, o direito deve se tornar musical. Ele estetiza seu aparelho de percepção, na medida em que não mais apenas ignora seus meios sociais como algo exterior (ruído) ou pressiona-os em sua racionalidade (re-entry), mas também os percebe como objetivamente sensíveis. Ele deve adquirir sensibilidade para o choro na sala de justiça, o grito dos sofredores ou os lemas de protesto clamados pelos movimentos sociais. E ele apenas se torna capaz disso se cria receptores em condições de perceber tais fenômenos.

Esta "guinada neorromântica" (Idem, p. 80) critica o encurtamento da racionalidade do direito em nome dos direitos sociais. Ela remove os ambientes sociais do status de meros exteriores. Aqui se encontram aqueles afetos e corpos - em uma palavra: o material - por meio dos quais o direito faz sua música. A sugestão consiste, sobretudo, em tornar esta música mimética, uma música que também é ajustada ao material e não o desfigura até o irreconhecível. No entanto, como é cultivada a capacidade para escutar e compor mimeticamente na sociedade funcionalmente diferenciada? É cada vez mais raro encontrar tais "bons ouvintes" - se seguimos, por exemplo, as investigações 
de Adorno em sua sociologia da música sobre o comportamento do ouvido "com o aburguesamento irrefreável da sociedade, a vitória do princípio da troca e do rendimento" (Adorno, 1975, p. 19). É certo que o ouvido pode, ele mesmo, ter um tipo de vontade própria mimética em comparação a outros tipos de percepção. Contudo, permanece provável que seu comportamento dominante afete a estetização do direito: "música como entretenimento", "escuta-ressentimento", "escuta emocional" (Idem). As modalidades de escuta no direito são pré-formadas pelas eficácias de seleção e repressão do sistema. A música não pode transformar, de modo imediato, a razão unidimensional em programa de contestação. Ela está "entrelaçada no conflito social" (Idem, p. 72). Seu potencial não reside no fato de que cure as contradições sociais, mas sim de que as conduza à representação. A escuta e a composição mimética no direito aqui abordadas permanecem, pois, um desiderato, que pode resultar apenas das contradições, ou seja, da confrontação de diferentes modos de percepção e composição legais. Desse modo, a estetização jurídica permanece política - e ela não está imune de, escutando e compondo, terminar em mera ideologia. Para formular mais precisamente: o que acontece quando Uli Hoeneß e Joseph Sepp Blatter choram no tribunal de justiça?

O programa da estetização pode ser relacionado no próximo passo também com a própria forma do direito. Junto com a crítica ao direito em nome do material social do qual ele, ao final, é tecido, pode ser constituído, novamente, um modo interno de observação jurídica. Aqui, portanto, a estetização do direito deve ser compreendida principalmente sob a ideia de que a forma jurídica perde seu caráter autônomo. Ela é dissolvida nas relaçôes de comunicação social. Este é um projeto estético na medida em que não visa simplesmente a suprimir ou dissolver politicamente o direito; antes se trata de indicar onde o direito entra no jogo. O direito é, então, estetizado, na medida em que ascende à poesia, à dança ou à música: "no lugar da comunicação, lendas e questôes (legalmente proibidas), entra a percepção do ritmo e da música” (Fögen, 2007, p. 125). Cornelia Vismann volta-se à cultura jurídica de Esparta. Ela encontra lá um "direito nomos, que canta e dança, em vez de ser escrito e comentado" (Vismann, 2012, p. 39). O ponto de partida é diferente daquele do programa neorromântico. A autodissolução do sistema do direito começa com seu uso estético. Ou, dito de outra forma: o direito permanece, é certo, sistema, mas está aberto a uma estetização que o priva de seu potencial de violência e autonomização. $O$ preço para uma estetização assim compreendida é alto. O direito perde sua normatividade imanente: "Quando as potencialidades começam a jogar (e tornam-se forças), sua normatividade imanente se dissolve. Quem é 
15. Hoje, desenham-se aqui duas direçôes: de um lado, a tentativa de suplementar (Stäheli, 2000) ou reescrever (Möller, 2014) a teoria dos sistemas com a teoria da hegemonia pós-marxista; de outro, a tentativa de voltar ao papel dominante do sistema econômico capitalista na sociedade moderna (Bachur, 2013; Jessop, 2008; Prien, 2013).
16. "Quando se procura simplesmente liberdade subjetiva, princípios seriais e aleatoriedade diante da técnica dodecafônica, portanto, absorver novamente a atonalidade livre no sentido da expectativa de Schönberg, então quase que necessariamente a reação desmorona" (Adorno, 2003, p. 271). esteticamente livre não é mais livre na prática: não pode mais nada, não pode mais deixar que nada dê certo" (Menke, 2013a, pp. 156 e ss.). Com isso, o direito corre o risco de desativar as forças de sua racionalidade formal. Como instrumento ou técnica para transformar relações sociais, ele não serve para nada. Ele não pode, simplesmente, mais nada.

\section{Droit informel}

Como ficou claro na passagem pelas diferentes fórmulas alternativas, permanecemos na aporia fundamental. A sociedade é criticada em nome do direito e o direito, em nome da sociedade. Se a doutrina crítica do Estado de direito já tinha essa aporia como ponto de partida, novas fórmulas alternativas estão em atividade. As reflexões acerca de um outro direito começam, assim, a evitar determinados pressupostos da teoria dos sistemas ortodoxa. Elas se conectam aos programas neorromânticos, procuram por justiça ou refletem sobre uma anulação estética do direito. Em todos os níveis, contudo, tornou-se claro que é necessária uma leitura sensível de análise de poder da diferenciação funcional ${ }^{15}$. Apenas assim podem ser encontradas diferenciações entre a forma de direito existente e um outro direito, entre as melodias legais em colisão. Também a força transformativa da crítica jurídica permanece até agora em aberto. Ela indica o espaço para um outro direito, mas deve, contudo, enfrentar alguns obstáculos. Isso não deve levar novamente à dissolução da aporia de forma jurídico-conservadora ou de forma jurídico-niilista. É essencial suportar a aporia e desdobrá-la adiante. Pois completamente sem justiça e romantismo, a crítica também não resulta em nada.

Para concluir, gostaria de fazer uma sugestão a partir da obra tardia de Theodor W. Adorno a respeito de uma musique informelle, que trabalha a relação de forma e crítica por meio de uma sensível análise de poder que é, de certo modo, estratégica. Em suas observações sobre a música informal, Adorno tenta tornar concebível de que maneira o primado da forma musical poderia ser dissolvido. A musique informelle é "uma música que se desprendeu de todas as formas que a opõem externa, abstrata, rigidamente, mas que, totalmente livre de imposições heterônomas e estranhas a ela, ainda assim constitui-se em fenômeno obrigatoriamente objetivo, não em regularidades nele [no fenômeno] memorizadas" (Adorno 1978b, p. 496). Esta seriedade em relação ao caráter mimético da expressão musical não é alcançada com mera espontaneidade no sentido de uma atonalidade livre ${ }^{16}$. A musique informelle primeiro supera a forma, para depois poder transcendê-la. Nessa medida, ocorre uma espécie de transição. 
Primeiro o "endurecimento" da forma distancia a música da sociedade, faz dela um campo de jogo com vontade própria (Adorno, 1976, pp. 28, 47 e ss.). Daí, a forma pode então transpor-se na sua dissolução: “mas a dominação material deve [...] intensificar-se autocriticamente, até que ela não aconteça mais em uma matéria heterogênea. Ela deve se tornar uma forma de reação àqueles ouvidos compositores que de certo modo se apropriam passivamente da tendência do material" (Adorno, 1978b, p. 537). É essencial, então, cuidar da forma, desdobrá-la, rompê-la ou retornar novamente a ela ${ }^{17}$. Ela deve ser instalada estrategicamente ou ainda novamente descoberta. Estas são condições para que a autonomização possa se transpor corretamente também na música livre. Então, a forma ainda é utilizada apenas para legitimar uma relação mimética com o ambiente social ${ }^{18}$. A musique informelle permanece "irreconciliável" em relação à indústria cultural e à sociedade capitalista (Idem, p. 538). Ela leva em seu bojo até mesmo um potencial de violência: "Caso a comunicação quisesse hoje a interferência da obra de arte no não artístico, ela deveria tapear a comunicação na face, não respeitar suas condições" (Idem, ibidem).

Pode-se, pois, refletir sobre o que isto poderia significar para um projeto do droit informel pensado de maneira semelhante. Não seria suspensa a aporia crítica do direito; antes, o caráter inconciliável de um droit informel sugere outra vez que o movimento de transcendência depende de uma sensível perspectiva de análise de poder. Sem uma contemplação das relações de poder e das contradições antagônicas não se pode explicar a que o "tapa na cara" dado pelo direito e no direito é direcionado. E, ainda mais importante: se ele realmente acerta.

\section{Referências Bibliográficas}

Adorno, Theodor W. ([1962] 1975), Einleitung in die Musiksoziologie. Frankfurt, Suhrkamp. . ([1949] 1976), Philosophie der neuen Musik. Frankfurt, Suhrkamp. . ([1966] 1978a), "Form in der neuen Musik". In: Tiedemann, Rolf (org.). Adorno: Musikalische Schriften I-III. Frankfurt, Suhrkamp, pp. 607-627. . ([1961] 1978b), "Vers une musique informelle". In: Tiedemann, Rolf (org.).

Adorno: Musikalische Schrift I-III. Frankfurt, Suhrkamp, pp. 493-540. . (2003), “Schwierigkeiten I. Beim Komponieren”. In: Tiedemann, Rolf (org.). Adorno: Gesammelte Schriften Band 17. Frankfurt, Suhrkamp, pp. 253-273. . ([1964] 2008), Philosophische Elemente einer Theorie der Gesellschaft. Frankfurt,

Suhrkamp.
17. Isso fica especialmente claro nas discussões de Adorno acerca das diferentes tentativas de dissoluçāo formal na nova música (Adorno, 1978a).

18. Não para executar a vontade do compositor ou do intérprete do direito. 
Amstutz, Marc. (2013), "Der zweite Text: Für eine Kritische Systemtheorie des Rechts". In: Amstutz, Marc \& Fischer-Lescano, Andreas (orgs.). Kritische Systemtheorie: Zur Evolution einer normativen Theorie. Bielefeld, transcript, pp. 365-395.

BACHUR, João P. (2013), Kapitalismus und funktionale Differenzierung. Baden-Baden, Nomos.

Benjamin, Walter. ([1921] 1991), “Zur Kritik der Gewalt”. In: . Gesammelte Schriften II. 1. Frankfurt, Suhrkamp, pp. 179-203.

Berman, Harold J. (1991), Recht und Revolution: die Bildung der westlichen Rechtstradition. Frankfurt, Suhrkamp.

BLECHER, Michael. (1991), Zu einer Ethik der Selbstreferenz oder: Theorie als Compassion. Möglichkeiten einer Kritischen Theorie der Selbstreferenz von Gesellschaft und Recht. Berlim, Duncker \& Humblot.

BRUnkhorst, Hauke. (2011), "Legitimationsverhältnisse”. In: EBERL, Oliver (org.). Transnationalisierung der Volkssouveränität: Radikale Demokratie diesseits und jenseits des Staates. Stuttgart, Franz Steiner, pp. 317-349.

. (2014), Critical theory of legal revolutions. Londres/Nova York, Bloomsbury Academic.

BUCKel, Sonja. (2007), Subjektivierung und Kohäsion: Zur Rekonstruktion einer materialistischen Theorie des Rechts. Weilerwist, Velbrück.

(2011), "Von der Selbstorganisation zur Gerechtigkeitsexpertokratie: Zum Wandel der Prozeduralisierung des Allgemeinen”. In: EBERL, Oliver (org.). Transnationalisierung der Volkssouveränität: Radikale Demokratie diesseits und jenseits des Staates. Stuttgart, Franz Steiner, pp. 33-56.

Derrida, Jacques. (1991), Gesetzeskraft: Der “mystische Grund der Autorität”. Frankfurt, Suhrkamp.

ENGELS, Friedrich. ([1877] 1962), "Herrn Eugen Dühring's Umwälzung der Wissenschaft”. Berlim, Dietz, pp. 1-303 (Marx-Engels Werke, n. 20).

Femia, Pasquale. (2013), “Infrasystemische Subversion”. In: Amstutz, Marc \& FischerLesCANo, Andreas (orgs.). Kritische Systemtheorie: Zur Evolution einer normativen Theorie. Bielefeld, transcript, pp. 305-326.

Fischer-Lescano, Andreas. (2005), Globalverfassung: Die Geltungsbegründung der Menschenrechte. Weilerwist, Velbrück.

. (2009), "Kritische Systemtheorie Frankfurter Schule”. In: Calliess, Gralf-Peter; Fischer-Lescano, Andreas; Wielsch, Dan \& Zumbansen, Peer (orgs.). Soziologische Jurisprudenz. Berlim, W. de Gruyter, pp. 49-68.

. (2013a), "Postmoderne Rechtstheorie als kritische Theorie”. Deutsche Zeitschrift für Philosophie, 61 (2): 179-196.

. (2013b), Rechtskraft. Berlim, August-Verlag. 
Fischer-Lescano, Andreas \& MöLler, Kolja. (2012), Der Kampf um globale soziale Rechte: Zart wäre das Gröbste. Berlim, Wagenbach.

Fögen, Marie T. (2007), Das Lied vom Gesetz. Munique, Carl Friedrich von Siemens Stiftung.

Fraenkel, Ernst. ([1932] 1973), “Die politische Bedeutung des Arbeitsrechts". In: (org.). Reformismus und Pluralismus. Hamburgo, Hoffmann und Campe, pp. 60-72.

Francot-Timmermans, Lyana \& Christodoulidis, Emilios. (2011), "The normative turn in Teubner's systems theory of law". Netherlands Journal of Legal Philosophy, 3: $187-190$.

GonçAlves, Guilherme L. (2013a), Il rifugio delle aspettative: saggio sulla certezza del diritto. Lecce, Rovato Pensa Multimedia.

. (2013b), "Postkolonialismus und Systemtheorie: Eine Forschungsperspektive zum Recht im Süden?”. In: Tzaneva, Magdalena (org.). Nachtflug der Eule: 150 Stimmen zum Werk von Niklas Luhmann. Berlim, LiDi EuropEdition, pp. 125-158.

Hensel, Isabell. (2013), “Klangpotentiale: Eine Annäherung an das Rauschen des Rechts". In: Joerges, Christian \& Zumbansen, Peer Kurztitel (orgs.). Politische Rechtstheorie revisited: RudolfWiethölter zum 100. Semester. Bremen, ZERP, pp. 69-99. Holmes, Pablo. (2013), Verfassungsevolution in der Weltgesellschaft. Baden-Baden, Nomos. Horst, Johan. (2013), "Politiken der Entparadoxierung: Versuch einer Bestimmung des Politischen in der funktional ausdifferenzierten Weltgesellschaft". In: Aмstutz, Marc \& Fischer-LesCANo, Andreas (orgs.). Kritische Systemtheorie: Zur Evolution einer normativen Theorie. Bielefeld, transcript, pp. 189-212.

Jessop, Bob. (2008), "Zur Relevanz von Luhmanns Systemtheorie und von Laclau und Mouffes Diskursanalyse für die Weiterentwicklung der materialistischen Staatstheorie”. In: Hirsch, Joachim; Kannankulam, John \& Wissel, Jens (orgs.). Der Staat der bürgerlichen Gesellschaft: zum Staatsverständnis von Karl Marx. Baden-Baden, Nomos, pp. 157-179.

Kirchheimer, Otto. (1976), "Zur Staatslehre von Sozialismus und Bolschewismus". In: LuthardT, Wolfgang (org.). Von der Weimarer Republik zum Faschismus: Die Auflösung der demokratischen Rechtsordnung. Frankfurt, Suhrkamp, pp. 32-52.

Körner, Ekkehard. (2008), "Theoriewallungen des Populären”. Taz, 14 jan.

Koskenniemi, Martti. (2002), Kritik der Souveränität. Cambridge, Cambridge University Press.

. (2005), "International law in Europe: between tradition and renewal". European Journal of International Law, 16 (1): 113-124.

Liste, Philip. (2012), Völkerrecht-Sprechen: Die Konstruktion demokratischer Völkerrechtspolitik in den USA und der Bundesrepublik Deutschland. Baden-Baden, Nomos. 
LoIck, Daniel. (2012), Kritik der Souveränität. Frankfurt, Campus.

Luhmann, Niklas. (1984), Soziale Systeme: Grundriß einer allgemeinen Theorie. Frankfurt, Suhrkamp.

.(1985), "Einige Probleme mit 'reflexivem Recht"'.Zeitschrift für Rechtssoziologie, $6(1): 1-18$.

. (1993a), Das Recht der Gesellschaft. Frankfurt, Suhrkamp.

. (1993b), “Observing re-entries”. Graduate Faculty Philosophy Journal, 16 (2): 485-498. . (1994), Die Wirtschaft der Gesellschaft. Frankfurt, Suhrkamp.

Luxemburg, Rosa. (1966), “Sozialreform oder Revolution?”. In: Flechtheim, Ossip Kurt (org.). Rosa Luxemburg: Politische Schriften I. Frankfurt, Europäische Verlagsanstalt, pp. 47-134.

Manderson, Desmond. (2013), "Making a point and making a noise: a punk prayer". Law, Culture and the Humanities, 13 jun. [online], pp. 1-13.

. (2014), "Towards Law and Music". Law and Critique, 25: 1-7.

Marx, Karl. ([1875] 1962), “Kritik des Gothaer Programms”. Berlim, Dietz, pp. 13-32 (Marx-Engels Werke, n. 19).

.([1864] 1972), Das Kapital. Berlim, Dietz, pp. 13-32 (Marx-Engels Werke, n. 23). . ([1843] 1972), “Zur Judenfrage”. Berlim, Dietz, pp. 347-377. (Marx-Engels

Werke, n. 1).

Maus, Ingborg. (1986), “Die Basis als Überbau oder Realistische Rechtstheorie”. In: (org.). Rechtstheorie und politische Theorie im Industriekapitalismus. Munique, W. Fink, pp. 247-276.

. (1992), Zur Aufklärung der Demokratietheorie: rechts-und demokratietheoretische Überlegungen im Anschluss an Kant. Frankfurt, Suhrkamp.

Menke, Christoph. (2013a), Die Kraft der Kunst. Berlim, Suhrkamp. . (2013b), Recht und Gewalt. Berlim, August-Verlag. (2014), "Die Möglichkeit eines anderen Rechts". Deutsche Zeitschrift für Philosophie, 62: 136-143.

Möller, Kolja. (2014), Formwandel der Verfassung: Die postdemokratische Verfasstheit des Transnationalen. Tese de doutorado. Flensburgo, Universität Flensburg.

Neumann, Franz L. ([1937] 1967), “Der Funktionswandel des Gesetzes im Recht der bürgerlichen Gesellschaft". In: (org.). Demokratischer und autoritärer Staat. Beiträge zur Soziologie der Politik. Frankfurt, Europäische Verlagsanstalt, pp. 7-57. . (1980), Die Herrschaft des Gesetzes. Frankfurt, Suhrkamp.

Neves, Marcelo. (2001), "From the autopoiesis to the allopoiesis of law". Journal of Law and Society, 28 (2): 242-264.

Opitz, Sven. (2012), An der Grenze des Rechts: Inklusion/Exklusion im Zeichen der Sicherheit. Weilerswist, Velbrück. 
Paschukanis, E. ([1929] 2003), Allgemeine Rechtslehre und Marxismus. Freiburg, Ça ira-Verlag.

Philippopoulos-Minalopoulos, A. (2013), "Critical autopoiesis and the materiality of law". International Journal for the Semiotics of Law, 27 (2): 389-418.

Prien, T. (2013), "Kritische Systemtheorie und materialistische Gesellschaftstheorie”. In: Amstutz, Marc \& Fischer-Lescano, Andreas (orgs.). Kritische Systemtheorie: Zur Evolution einer normativen Theorie. Bielefeld, transcript, pp. 81-98.

Renner, Moritz. (2011a), "Death by complexity: the crisis of law in world society". In: Kjaer, Poul; Febbrajo, Alberto \& Teubner, Gunther (orgs.). The financial crisis in constitutional perspective: the dark side of functional differentiation. Oxford, Bloomsbury, pp. 93-112.

.(2011b), Zwingendes transnationales Recht: zur Struktur der Wirtschaftsverfassung jenseits des Staates. Baden-Baden, Nomos.

SaAvedra, M. B. (2014), "Social rights and globalization: what can we learn from interwar constitutionalism?". Law and Society Association 50th Annual Conference. Minneapolis, MN, 29 maio- $1^{\circ}$ jun.

STÄHELI, Urs. (1998), “Politik der Entparadoxierung: zur Artikulation von Hegemonieund Systemtheorie". In: Marchart, Oliver (org.). Das Undarstellbare der Politik. Zur Hegemonietheorie Ernesto Laclaus. Viena, Turia \& Kant, pp. 52-66.

. (2000), Sinnzusammenbrüche: Eine dekonstruktive Lektüre von Niklas Lubmanns Systemtheorie. Weilerswist, Velbrück.

TetZlaff, Thilo. (2004), "Der Sound des Rechts: Rechtsästhetik und Rechtsakustik”. In: Kreuzbauer, Günther \& Augeneder, Silvia (orgs.). Der Juristische Streit: Recht zwischen Rhetorik, Argumentation und Dogmatik. Stuttgart, Franz Steiner, pp. 86-110.

Teubner, Gunther. (1983), "Substantive and reflexive elements in modern law". Law and Society Review, 17: 239-285.

. (1989), Recht als autopoietisches System. Frankfurt, Suhrkamp.

. (2000), "Privatregimes: Neo-Spontanes Recht und duale Sozialverfassungen in der Weltgesellschaft". In: Simitis, Spiros \& Weiss, Manfred (orgs.). Zur Autonomie des Individuums: Liber Amicorum Spiros Simitis. Baden-Baden, Nomos, pp. 437-453. (2006), "Die anonyme Matrix: Menschenrechtsverletzungen durch 'private' transnationale Akteure”. Der Staat, 45: 161-187.

. (2008), "Selbstsubversive Gerechtigkeit: Kontingenz- oder Transzendenzformel des Rechts?”. Zeitschrift für Rechtssoziologie, 29: 9-36.

(2012), Verfassungsfragmente: Gesellschaftlicher Konstitutionalismus in der Globalisierung. Berlim, Suhrkamp.

Viellechner, Lars. (2013), Transnationalisierung des Rechts. Weilerwist, Velbrück.

Vismann, Cornelia. (2012), Das Schöne am Recht. Berlim, Merve. 
Texto enviado em 19/5/2015 e aprovado em 24/6/2015.

DOI: http://dx.doi.org/10.1590 10103-2070201526

Kolja Möller trabalha como pesquisador de pós-doutorado no polo de excelência Normative Orders, na Universidade de Frankfurt. Seus temas são política internacional, teoria jurídica e constitucionalismo global. Publicaçōes recentes: "A critical theory of transnational regimes: creeping managerialism and the quest for a destituent power", em Kerstin Blome, Andreas Fischer-Lescano, Hannah Franzki, Nora Markard e Stefan Oeter (orgs), Contested collisions: interdisciplinary inquiries into norm fragmentation in world society (2015) e Formwandel der Verfassung: Diepostdemokratische Verfasstheit des Transnationalen (2015). E-mail: kolja.moeller@ normativeorders.net.
Wiethölter, Rudolf. (2005), “Justifications of a Law of Society”. In: Perez, Oren \& Teubner, Gunther (orgs.). Paradoxes and inconsistencies in the law. Oxford, Bloomsbury, pp. 65-77.

\section{Resumo}

\section{Crítica do direito e teoria dos sistemas}

$\mathrm{O}$ artigo centra-se em abordagens da teoria crítica do sistema em relação ao direito e à sociedade; mostra como elas modificam a estrutura da teoria ortodoxa dos sistemas e discute a forma de crítica resultante. $\mathrm{O}$ argumento principal é de que a guinada luhmanniana à esquerda baseia-se em uma forma aporética da crítica que já foi predominante na crítica do direito da primeira geração da Escola de Frankfurt, notavelmente na obra de Franz L. Neumann, qual seja: a crítica à autorreferência do direito em nome da sociedade e - vice-versa - a crítica à sociedade moderna em nome de um sistema jurídico autônomo. Embora argumentem que esse modo de crítica é altamente produtivo, essas abordagens apresentam uma lacuna quando se trata dos antagonismos sociais e das relações de poder. Uma analogia com o raciocínio de Theodor W. Adorno sobre a relação entre forma e violência é introduzida a fim de contornar as falácias de uma guinada ou niilista ou afirmativa no direito e na sociedade.

Palavras-chave: Teoria crítica dos sistemas; Niklas Luhmann; Theodor W. Adorno, Critical legal studies; Musique informelle; Franz L. Neumann.

\section{Abstract}

\section{Critique of law and system theory}

This article focuses on critical system theory approaches to law and society. It reveals how these approaches modify the orthodox systems-theoretical framework and discusses the resulting mode of critique. The main argument is that the Left-Luhmannian turn draws on an aporetic mode of critique which was already prevalent in the legal critique of the early Frankfurt school, most notably in the work of Franz L. Neumann: It criticizes law's self-reference in the name of society and - vice versa - criticizes modern society in the name of an autonomous legal system. While it is argued that this mode of critique is highly productive, these approaches show a lacuna when it comes to social antagonisms and power relations. An analogy to Theodor W. Adornos reasoning on the relation of form and violence is introduced in order to circumvent the fallacies of an either nihilist or affirmative take on law and society.

Keywords: Critical systems theory; Niklas Luhmann; Theodor W. Adorno; Critical legal studies; Musique informelle; Franz L. Neumann. 